\title{
Perfil de Egressos de Residências Multiprofissionais em Saúde no Rio Grande do Sul
}

Profile of Graduates From Multiprofessional Health Residencies in Rio Grande do Sul

Perfil de los Egresados de las Residencias Multiprofesionales en Salud en el Rio Grande do Sul

Vera Lúcia Pasini

Ana Maria Ponzoni Pretto

Ana Marcela Sarria

Marcelo Francisco da Silva Cardoso

Universidade Federal do Rio Grande do Sul (UFRGS), Porto Alegre, RS, Brasil

Resumo

No Brasil, desde o final dos anos 70, as Residências em Saúde se constituem como uma possibilidade de formação para diferentes profissões da saúde, especialmente no Rio Grande do Sul (RS). Entretanto, somente no início dos anos 2000 a implantação de Programas de Residências Multiprofissionais em Saúde (RMS) é estimulada em âmbito nacional. Este artigo analisa o perfil de 72 profissionais egressos(as), no período de 2005 a 2014, de cinco programas de RMS desenvolvidos no RS. Os(as) participantes da pesquisa responderam a um formulário elaborado no FORMSUS do DATASUS composto de questões fechadas e abertas, analisadas com o uso do Software SPSS v. 18. A análise apresenta o perfil dos(as) egressos(as) participantes considerando as variáveis gênero, raça e cor, idade; cursos de graduação; instituições de graduação; inserção no mundo do trabalho em saúde e avaliação quanto à formação em RMS, apontando a relevância das RMS para a qualificação no trabalho no Sistema Único de Saúde (SUS).

Palavras-Chave: Residências Multiprofissionais em Saúde; Egressos(as); Saúde; Saúde Mental; Atenção Básica.

\begin{abstract}
In Brazil, since the end of the 1970s, Health Residency Programs have been a training possibility for distinct health careers, especially in the state of Rio Grande do Sul (RS). However, it was not until the early 2000s that the implementation of these programs was stimulated in the national scope. The participants filled a form on DATASUS FormSUS, and the answers were analyzed by means of SPSS v. 18. This paper analyses the profile of 72 residents who graduated between 2005 and 2014 from five Health Residency Programs
\end{abstract}


developed in the state. The analysis introduces the profile of the graduates considering the following variables: gender; race/skin color; age; undergraduate courses; undergraduate institutions; insertion in the health work world; appraisal of the training developed in the programs, indicating their relevance for the qualification of the work in the National Unified Health System.

Keywords: Multiprofessional Health Residency; Graduates; Health; Mental Health; Primary Care.

\section{Resumen}

En Brasil, desde los fines de la década de 70, las Residencias en Salud se constituyen como una posibilidad de formación para diferentes profesiones de la salud, en especial en el Rio Grande del Sur. Sin embargo, es solamente desde el principio de los años 2000 que se estimula, en ámbito nacional, la implementación del Programa de Residencia Multiprofesional en Salud (RMS). Este artículo produce un análisis del perfil de 72 profesionales egresados, en el periodo de 2005 a 2014, de cinco programas de RMS desarrollados en el Rio Grande del Sul (RS). Los participantes de la investigación respondieron a un formulario preparado en el FORMUSUS del DATASUS, que detenía preguntas cerradas y abiertas, y analizadas con el uso de los Softwares SPSS v. 18. El análisis presenta el perfil de los egresados participantes considerando las variaciones de género; raza/color; edad; cursos de graduación; instituciones de graduación; inserción en el mundo del trabajo en salud; Evaluación sobre la formación en RMS, y apunta la relevancia de las RMS para la cualificación en el trabajo en el Sistema Único de Salud (SUS).

Palabras clave: Residencias Multiprofesionales en Salud; Egresados; Salud; Salud Mental; Atención Básica.

\section{Introdução}

No Brasil o tema da formação de profissionais para operar o Sistema Único de Saúde (SUS) já se anuncia como um problema a ser enfrentado contemporaneamente à sua formulação legal como política pública, pois a Constituição Federal de 1988, em seu artigo 200, estabelece a competência do SUS de "ordenar a formação de Recursos Humanos na área da saúde" e "incrementar em sua área de atuação o desenvolvimento científico e tecnológico" (Constituição da República Federativa do Brasil, 1988). Estas atribuições são reforçadas na Lei Orgânica da Saúde (Lei n. 8.080, 1990) e podemos dizer que as décadas de 1980 e de 1990 foram décadas paradigmáticas para a saúde pública do Brasil, produzindo mudanças importantes nos modos de compreender e propor o cuidado em saúde. A criação do SUS representou a necessidade de novas formas de pensar, estruturar, desenvolver e produzir serviços e assistência em saúde, bem como de 
formar trabalhadores(as) em consonância com os princípios que passam a orientar o sistema (universalidade, acesso, integralidade da atenção à saúde, equidade, participação da comunidade, autonomia das pessoas e descentralização) (Machado, 2008).

No contexto da Reforma Sanitária a gestão do trabalho e da educação passou a ser uma discussão fundamental, pois os(as) trabalhadores(as) de saúde são elementos chave para a implementação e consolidação do SUS (Machado, 2008). Porém, sabemos que a formação em saúde, por muitos anos, seguiu reproduzindo uma visão reducionista do cuidado, voltada às doenças, aos procedimentos e às tecnologias especializadas, sem colocar em relevo uma perspectiva ampliada de saúde, na qual as tecnologias relacionais têm importante papel. Embora as tecnologias leves, referidas ao encontro singular com cada usuário(a), sejam apontadas como fundamentais no cuidado em saúde, prevalece uma concepção bastante referenciada às tecnologias duras e leveduras no tratamento (Merhy, 2002, Merhy \& Feuerwerker, 2009), ressaltando a importância do investimento em processos de formação de trabalhadores(as) que produzam transformações nos modos de pensar e fazer em saúde (Ceccim \&
Bilibio, 2002, Ceccim \& Feuerwerker, 2004, Feuerwerker, 2002).

$$
\text { Em 2003, o Governo Federal }
$$
retomou o princípio de que a saúde é um bem público, tal qual os(as) trabalhadores(as) atuantes no SUS. Nesse período foi criada, no âmbito do Ministério da Saúde, a Secretaria de Gestão do trabalho e da Educação em Saúde (SGTES) que possibilitou ao Ministério da Saúde assumir o papel, já definido na legislação, de gestor federal do SUS na formulação das políticas orientadoras da formação, desenvolvimento, distribuição, regulação e gestão dos(as) trabalhadores(as) de saúde no Brasil (Ministério da Saúde, 2004).

A SGTES surge com o intuito de transformar e qualificar as práticas de saúde, a organização das ações e dos serviços, a implementação de processos formativos e de práticas pedagógicas na formação e no desenvolvimento $\operatorname{dos}($ as) trabalhadores(as) de saúde. Uma de suas importantes ações naquele momento foi a criação da Política Nacional de Educação Permanente em Saúde (PNEPS), instituída pela Portaria GM/MS no 198, de 13 de fevereiro de 2004 (Portaria n. 198, 2004), como estratégia do SUS para a formação e o desenvolvimento de trabalhadores(as) para o setor. 
As Residências Multiprofissionais e em Área Profissional da saúde são algumas dentre as muitas estratégias da SGTES para produzir interferências nos processos de formação de trabalhadores(as) de saúde e reinvenção das práticas em saúde no SUS (Ministério da Saúde, 2005), propondo-se a oferecer aos(às) residentes a possibilidade de experimentação nos serviços de saúde, com o acompanhamento permanente de profissionais experientes. Levou-se em consideração a necessidade de inserção de jovens profissionais no sistema de saúde, pois a presença deles(as) era - e continua sendo - reduzida ou inexistente durante o período da graduação, especialmente na perspectiva da formação para o trabalho em equipes.

Gestores(as), formadores(as) e integrantes dos diferentes espaços de controle social esperavam que as residências multiprofissionais promovessem, ao mesmo tempo, a formação de novos(as) trabalhadores(as) afinados(as) com os pressupostos do SUS e a desestabilização das práticas obsoletas ainda presentes nos serviços, propiciando às próprias equipes que os(as) acolhem a revisitação das formas como concebem e exercem o cuidado em saúde. Neste sentido, investia-se na ampliação do olhar dos(as) trabalhadores(as) de saúde, comprometendo-os(as)

com

o

reconhecimento da necessidade do trabalho em equipe e da valorização da rede de serviços que compõe o sistema.

No Brasil as formações multiprofissionais em serviço (no formato de Residências em Saúde) já se constituem como uma possibilidade para diferentes profissões, além da Medicina, desde o final dos anos 70, especialmente no Rio Grande do Sul. Entretanto, somente após a constituição da SGTES a implantação de Programas de RMS é estimulada em âmbito nacional como parte da Política de Educação Permanente em Saúde/EPS, visando à ampliação da formação para todas as profissões da saúde (Brasil, 2007).

As RMS foram legalmente instituídas em 30 de junho de 2005, através da Lei n. 11.129 (2005). Em 2007 a Portaria Interministerial n. 45, de 12 de janeiro define as Residência Multiprofissional em Saúde e a Residência em Área Profissional da Saúde como

ensino de pós-graduação lato sensu destinado às profissões que se relacionam com a saúde, sob a forma de curso de especialização caracterizado por ensino em serviço, sob a orientação de profissionais de elevada qualificação ética e profissional, com carga horária entre 40 (quarenta) e 60 (sessenta) horas semanais (Portaria Interministerial n. 45, 2007, p. 2). 
As RMS tomam os serviços de saúde como cenários de práticas e espaços de vivência do trabalho em equipe, favorecendo o aprendizado coletivo no trabalho. Como é apontado por vários(as) autores(as) (Ceccim, 2004, Feuerwerker, 2003, Peduzzi, 2001), o trabalho em equipe tem sido uma estratégia importante para enfrentar o intenso processo de especialização na área da saúde, que tende a produzir fragmentação do cuidado.

As profissões previstas na composição das RMS são aquelas definidas pela Resolução $n^{\circ}$ 287/1998, do Conselho Nacional de Saúde (Resolução CNS n. 287, 1998): Biomedicina, Ciências Biológicas, Educação Física, Enfermagem, Farmácia, Fisioterapia, Fonoaudiologia, Medicina Veterinária, Nutrição, Odontologia, Psicologia, Serviço Social, Terapia Ocupacional e, posteriormente incluída, Saúde Coletiva.

Passados 15 anos desde o início do processo de maior fomento à criação de novos Programas de Residência Multiprofissional por parte dos Ministérios da Saúde e Educação brasileiros, considerando-se o investimento financeiro realizado até o momento e o risco de desmonte dessa estratégia deformação no atual cenário político do país, entendemos ser de fundamental relevância conhecer o perfil dos(as) profissionais egressos(as) de programas de RMS e suas inserções no mundo do trabalho em saúde.

Neste artigo apresentamos alguns resultados de uma pesquisa desenvolvida desde 2016 com programas de RMS desenvolvidos no estado do Rio Grande do Sul, no qual descrevemos e analisamos o perfil dos(as) profissionais egressos(as) de programas realizados em cenários de formação da Atenção Básica (tomada nas diferentes nomenclaturas com as quais se costuma referir esta área) e da Saúde Mental. São analisadas também as características de suas inserções atuais no campo da saúde, especialmente no SUS, assim como suas avaliações a respeito da importância dessa formação em suas trajetórias profissionais.

\section{Método}

$\mathrm{O}$ artigo parte de dados produzidos no âmbito do projeto "Residências Multiprofissionais em Saúde: onde estão os profissionais egressos e que dispositivos de cuidado em saúde mental estão produzindo?", discutindo elementos do perfil dos(as) egressos(as), através da análise descritiva dos dados quantitativos produzidos no âmbito da pesquisa. Os dados são apresentados em valores absolutos e percentagens relativas, verificando a prevalência nas categorias através da estatística descritiva (Sampieri, Collado \& Lucio, 2013), realizada com 
suporte do software SPSS V.18.0 (SPSS Inc., 2009)

As informações foram solicitadas a sete (7) programas de residência realizados no estado do RS, identificados através dos editais de seleção, que ofertaram vagas para formações nas ênfases em Atenção Básica/Atenção Primária à Saúde/Saúde da Família/Saúde Comunitária e Saúde Mental/Saúde Mental Coletiva no período entre 2003 e 2012, tendo egressos entre 2005 a 2014. O recorte de tempo analisado se deve ao escopo do projeto de pesquisa ao qual o artigo se vincula.

O referido projeto foi aprovado pelos Comitês de Ética em Pesquisa (CEP) do Instituto de Psicologia da UFRGS sob parecer $\mathrm{n}^{\circ}$ 1.658.645; da Universidade Luterana do Brasil (ULBRA), parecer $n^{\circ}$ 2.084.954; da Escola de Saúde Pública do Rio Grande do Sul (ESP), parecer $\mathrm{n}^{\circ}$ 2.134.648; da Universidade Federal do Rio Grande (FURG), parecer $n^{\circ}$ 2.788.617; e do Grupo Hospitalar Conceição (GHC), parecer $\mathrm{n}^{\mathrm{o}} 2.978 .441$ e recebeu apoio financeiro do $\mathrm{CNPq}$ através da Chamada Universal 01/2016 - Faixa A.

Tivemos retorno das informações solicitadas por parte de cinco das instituições formadoras, a partir das quais se compõe o universo analisado neste artigo. Atenderam ao convite para participar da pesquisa 72 profissionais egressos(as) de RMS, representando um percentual de $8,32 \%$ do total de egressos(as) dos programas no período de análise. Conforme informações fornecidas pelas coordenações dos programas de Residências participantes, o número de profissionais que concluíram a formação no período estudado foi de 865 pessoas, sendo: 342 no GHC; 422 na ESP; 62 na UFRGS; 17 na HCPA; 22 na ULBRA. Na composição amostral aqui apresentada, 06 são egressos(as) da ESP/RS; 47 do GHC; 04 do HCPA; 14 da UFRGS e 01 da ULBRA.

Procedeu-se a busca de informações sobre os(as) egressos(as) a partir das coordenações dos programas (nomes e contatos dos(as) egressos(as)) e, posteriormente, foram feitos os convites diretamente aos(às) egressos(as) identificados, por e-mail e redes sociais, para participar da pesquisa. A partir do aceite ao convite e aos termos do Termo de Consentimento Livre e Esclarecido (TCLE) anexo à mensagem, os(as) participantes acessavam um formulário elaborado no FORMSUS do DATASUS. O formulário contém 17 questões fechadas (com opções de respostas) e 31 questões abertas (o participante escreve a resposta), totalizando 48 perguntas, sendo que algumas delas estão condicionadas a respostas anteriores e, portanto, nem 
todos(as) os(as) participantes responderam a integralidade das questões formuladas. $\mathrm{O}$ projeto de Pesquisa envolve, ainda, a realização de grupos de discussão com egressos(as) selecionados(as) a partir das respostas ao formulário, entrevistas com gestores(as) contratantes dos(as) egressos(as) e observações do cotidiano do trabalho dos(as) profissionais egressos(as) em seus locais de trabalho.

Os resultados aqui apresentados se referem apenas às questões do formulário que apresentam elementos para a produção de um "perfil dos(as) residentes egressos(as)" participantes da pesquisa, sendo eles: gênero, raça/cor, faixa etária de ingresso na residência, ano de conclusão na graduação, ano de ingresso e ano de conclusão da RMS, cursos de graduação, local de moradia e graduação, inserção no mundo do Trabalho em saúde, avaliação quanto à formação em RMS.

\section{Resultados e Discussão}

Apresentamos a seguir uma tabela com os principais elementos do perfil que analisaremos ao longo deste artigo:

Tabela 1

Valores de Frequência e Porcentagens Relativas Para as Variáveis Descritivas do Perfil da Amostra Investigada

\begin{tabular}{ll|l}
\hline Gênero & Frequência & Porcentagem \\
\hline Feminino & 57 & 79,2 \\
\hline Masculino & 15 & 20,8 \\
\hline Raça/cor & Frequência & Porcentagem \\
\hline Branco & 55 & 76,4 \\
\hline Não informado & 9 & 12,5 \\
\hline Pardo & 5 & 6,9 \\
\hline Não sei/prefiro não declarar & 2 & 2,8 \\
\hline Preto & 1 & 1,4 \\
\hline Faixa etária de ingresso & na Frequência & Porcentagem \\
\hline residência & & \\
\hline $20-28$ anos & 60 & 83,3 \\
\hline Acima de 29 & 12 & 16,7 \\
\hline Ano de conclusão da graduação & Frequência & Porcentagem \\
\hline 2008 & 17 & 23,6 \\
\hline 2007 & 12 & 16,7 \\
\hline 2006 & 10 & 13,9 \\
\hline 2009 & 10 & 13,9 \\
\hline 2010 & 8 & 11,1 \\
\hline
\end{tabular}




\begin{tabular}{|c|c|c|}
\hline 2011 & 5 & 6,9 \\
\hline 2005 & 4 & 5,6 \\
\hline 2004 & 3 & 4,2 \\
\hline 2000 & 1 & 1,4 \\
\hline 2003 & 1 & 1,4 \\
\hline 2012 & 1 & 1,4 \\
\hline Ano de ingresso na RMS & Frequência & Porcentagem \\
\hline 2008 & 17 & 23,6 \\
\hline 2010 & 12 & 16,7 \\
\hline 2009 & 11 & 15,3 \\
\hline 2012 & 11 & 15,3 \\
\hline 2011 & 10 & 13,9 \\
\hline 2006 & 7 & 9,7 \\
\hline 2007 & 3 & 4,2 \\
\hline 2005 & 1 & 1,4 \\
\hline Ano de conclusão da RMS & Frequência & Porcentagem \\
\hline 2010 & 16 & 22,2 \\
\hline 2012 & 13 & 18,1 \\
\hline 2011 & 11 & 15,3 \\
\hline 2014 & 11 & 15,3 \\
\hline 2013 & 9 & 12,5 \\
\hline 2008 & 5 & 6,9 \\
\hline 2009 & 4 & 5,6 \\
\hline 2007 & 3 & 4,2 \\
\hline
\end{tabular}

\section{Gênero:}

Entre os(as) 72 participantes, observa-se uma predominância de mulheres, sendo que $79,2 \%$ informam gênero feminino e $20,8 \%$ gênero masculino, não havendo referência à outra orientação de gênero ou negativa de resposta à questão. Esse dado é compatível com estudos de perfil de egressos(as) de RMS (Goulart, Silva, Oliveira, Bolzan, \& Guido, 2012) e com outros estudos que apontam para a feminilização das profissões de saúde como uma tendência mundial desse campo (Bruschini, 2007,
Gadelha, Noronha, \& Pereira, 2012, Girardi \& Carvalho, 2002, Machado, 2000), sendo esta também uma realidade brasileira, onde a participação das mulheres no mundo do trabalho cresceu muito a partir da década de 1970 (Quirino, 2012).

Conforme indica a literatura é possível dizer que, no caso brasileiro, as mulheres constituem maioria em diversos cursos da área da saúde e, entre todos os setores de atividade econômica, o setor de serviços de saúde é o que mostra a maior participação de mulheres na composição 
do emprego (Bruschini, 2007, Gadelha et al., 2012).

Segundo Quirino (2012) os dados do Instituto Brasileiro de Geografia e Estatística (IBGE) apontam o acréscimo de mais de 10 milhões de trabalhadoras entre 1976 e 2010, ocupando destaque entre as profissões com maior escolaridade. Especialmente no que se refere ao nível superior, entre as pessoas da faixa etária mais jovem, de 25 a 44 anos de idade (caso dos(as) egressos(as) das RMS, como veremos a seguir), o percentual de mulheres que completou a graduação atingiu $21,5 \%$, indicador $37,9 \%$ superior ao dos homens. Entretanto, ainda segundo o Instituto Brasileiro de Geografia e Estatística (IBGE, 2018a), constatam-se desigualdades entre mulheres por cor ou raça, sendo o percentual de mulheres brancas com ensino superior completo 2,3 vezes maior do que o de mulheres pretas ou pardas. Se compararmos este dado entre homens pretos ou pardos e mulheres brancas este dado mostra ainda maior iniquidade, pois o percentual de mulheres brancas com ensino superior é três vezes maior do que o encontrado para homens pretos ou pardos, evidenciando este grupo enquanto aquele com os piores resultados em relação à escolaridade (IBGE, 2018a).

Raça/Cor:
Quanto ao quesito raça/cor, 55 $(76,4 \%)$ pessoas se autodeclaram brancas; $5(6,9 \%)$ pardas; e apenas $1(1,4 \%)$ preta; do total de participantes, 2 responderam não sei/prefiro não declarar $(2,8 \%)$ e 9 pessoas não informaram (12,5\%). Ressaltamos que, inicialmente, não havíamos incluído questão sobre o quesito raça/cor no formulário, porém após o retorno de alguns respondentes, avaliamos a importância de considerar a questão racial como um elemento do perfil dos(as) egressos(as), dada a relevância das discussões sobre o racismo que estrutura a sociedade brasileira, marcando também o campo do trabalho em saúde (Almeida, 2018, Schucman, 2014). Assim, enviamos aos(às) participantes a pergunta sobre esta questão, não havendo retorno de todos(as) aqueles(as) que inicialmente haviam respondido ao formulário.

Conforme aponta o Instituto Brasileiro de Geografia e estatística (IBGE, 2018b) o mercado de trabalho brasileiro, resultado de seu processo histórico, impõe a determinados grupos populacionais uma inserção mais precária do que a outros, tornando-os mais vulneráveis às questões econômicas, implicando em perdas de melhores condições de vida. As dificuldades de homens e mulheres negros(as) darem continuidade à formação profissional, 
promove acirramento de desigualdades que marcam nossa organização social, pois os empregos por profissionais de nível superior no campo da saúde seguem sendo ocupados, majoritariamente, por homens e mulheres brancos(as), cabendo à população negra os empregos de nível médio, com pouco reconhecimento e piores remunerações.

Lembramos que é somente em 2010 que o Brasil institui a Lei n. 12.288 (2010), denominada de Estatuto da Igualdade Racial (Brasil, 2010), que prevê a implementação de uma política de igualdade racial através de diversas ações afirmativas que pretendem promover um tratamento materialmente isonômico à etnia negra. Embora a Lei n. 12.990 (2014) estabeleça que $20 \%$ (vinte por cento) do total das vagas oferecidas nos concursos públicos para provimento de cargos efetivos e empregos públicos no âmbito da administração pública federal, das autarquias, das fundações públicas, das empresas públicas e das sociedades de economia mista controladas pela União deve ser reservada à população negra, a regra não tem sido instituída na maioria dos programas de RMS.
Idade:

Com relação à faixa etária dos(as) ingressos(as) na residência, 60 pessoas estão no intervalo de maior prevalência $(83,3 \%), \operatorname{dos} 20$ a 28 anos, sendo que somente 12 egressos(as) (16,7\%) ingressaram na residência com idade acima dos 29 anos.

Conforme Lei n. 11.129 (2005), em seu Art. 15, o programa de bolsas das residências deveria dar prioridade aos menores de 29 (vinte e nove) anos para ingresso nas residências. Ainda com base na lei referida acima, a residência tem por objetivo "favorecer a inserção qualificada dos jovens profissionais da saúde no mercado de trabalho, particularmente em áreas prioritárias do Sistema Único de Saúde" (Lei n. 11.129, 2005, Art. 13- § 1º, online), o que condiz com os dados encontrados acerca do tempo relativo ao término da graduação e ao ingresso na residência: $60(83,3 \%)$ de 0 a 2 anos; 11 $(15,3 \%)$ de 2 a 5 anos; e apenas $1(1,4 \%)$ ingressou na residência 8 anos após a graduação. Nesse sentido, os programas de residência estariam cumprindo com os objetivos em sua criação de, através da formação, favorecer a inserção de jovens trabalhadores(as) no campo da saúde. 
Cursos de graduação:

Tabela 2

Valores de Frequência e Porcentagens Relativas Referente ao Curso de Graduação

\begin{tabular}{ll|l}
\hline & Frequência & Porcentagem \\
\hline Enfermagem & 17 & 23,6 \\
\hline Psicologia & 14 & 19,4 \\
\hline Serviço Social & 11 & 15,3 \\
\hline Odontologia & 9 & 12,5 \\
\hline & & \\
Educação Física & 6 & 8,3 \\
\hline Nutrição & 6 & 8,3 \\
\hline Farmácia & 4 & 5,6 \\
\hline Terapia Ocupacional & 2 & 2,8 \\
\hline Fisioterapia & 1 & 1,4 \\
\hline Fonoaudiologia & 1 & 1,4 \\
\hline Pedagogia/Bacharel Teatro & 1 & 1,4 \\
\hline
\end{tabular}

Os(as) egressos(as) participantes da pesquisa realizaram suas formações em programas com ênfases em Atenção Básica/Atenção Primária à Saúde/Saúde da Família/Saúde Comunitária e Saúde Mental/Saúde Mental Coletiva, sendo oriundos(as) de cursos de graduação bastante variados, considerando o aspecto multiprofissional da residência. As respostas mostraram a participação de profissionais vindos de 12 cursos diferentes: $17 \quad(23,6 \%) \quad$ cursaram Enfermagem; 14 (19,4\%) Psicologia; 11 $(15,3 \%)$ Serviço Social; 9 (12,5\%) Odontologia; $6(8,3 \%)$ dos cursos de Nutrição; 6 (8,3\%) de Educação Física; 4
(5,6\%) da Farmácia; 2 (2,8\%) da Terapia Ocupacional; e $1(1,4 \%)$ de cada um dos cursos de Fonoaudiologia, Fisioterapia, Pedagogia e Bacharelado em Teatro, sendo as duas últimas não consideradas "profissões da saúde" (Resolução CNS n. 287, 1998), mas áreas afins que contribuem especialmente com o trabalho em Saúde Mental.

Considerando as cinco diferentes instituições das quais provêm os(as) respondentes da pesquisa, no cruzamento com as áreas de ênfase foco dessa pesquisa, $45(62,5 \%)$ realizaram a formação com ênfase em Atenção Básica (considerando as diferentes nomenclaturas recebidas por este campo no RS: Atenção 
Primária; Saúde da Família e Comunidade; Atenção Básica em Saúde Coletiva; Saúde da Família; Saúde Comunitária) e 27 (37,5\%) realizaram formação em Saúde Mental (ou Saúde Mental Coletiva).

Ainda sobre a graduação, dos(as) egressos(as) que acessamos, 42 (58,3\%) concluíram sua graduação em instituições públicas e $30(41,7 \%)$ em instituições privadas.

Em estudo sobre a formação em Psicologia e a inserção no SUS, Guareschi, Scisleski, Reis, Dhein e Azambuja (2014) discutem o direcionamento de ementas, conteúdos e bibliografias dos programas das disciplinas de 6 (seis) cursos de Psicologia no estado do RS de universidades que possuíam egressos(as) vinculados(as) às RMS. São apontadas mudanças produzidas a partir das Diretrizes Curriculares Nacionais para os cursos de graduação da área da saúde na formação dos profissionais da Psicologia, no que diz respeito à preparação para a atuação no SUS, especialmente em cursos que se propõem a deslocar o enfoque das práticas voltadas a uma clínica liberal privada para a perspectiva da Saúde
Coletiva. Algumas das questões apontadas para pensar esse deslocamento vão na direção da necessidade de romper com a dicotomização produzida entre as concepções de físico e psíquico, propiciando uma formação voltada à integralidade e à equidade do cuidado em saúde, princípios importantes do SUS. Outro elemento importante é a desconstrução das barreiras impostas pelas especificidades das áreas de conhecimento e o rompimento das fronteiras identitárias, visto que a integralidade somente se faz possível através da composição em equipes transdisciplinares; além disso, aponta-se a necessidade de um posicionamento ético/político implicado com as condições de existência, com reconhecimento dos determinantes históricos e sociais da produção de sujeitos.

A importância dos aspectos apontados por Guareschi et al. (2014) podem ser expandidos para o perfil de formação dos(as) demais profissionais da área da saúde, pois a capacidade de oferecer atenção integral é fundamental para a conquista da integralidade na atenção à saúde.

\section{Localidade de origem e graduação:}

Tabela 3

Valores de Frequência e Porcentagens Relativas Referente à Naturalidade e 
Residência Atual

\begin{tabular}{ll|l}
\hline Naturalidade & Frequência & Porcentagem \\
\hline $\begin{array}{l}\text { Municípios do interior do } \\
\text { RS }\end{array}$ & 40 & 55,6 \\
\hline Porto Alegre & 20 & 27,8 \\
\hline não informado & 7 & 9,7 \\
\hline Outros estados & 5 & 6,9 \\
\hline Reside atualmente & Frequência & Porcentagem \\
\hline Porto Alegre & 46 & 63,9 \\
\hline $\begin{array}{l}\text { Municípios do interior do } \\
\text { RS }\end{array}$ & 11 & 15,3 \\
\hline Outros estados & 10 & 13,9 \\
\hline $\begin{array}{l}\text { Região metropolitana de } \\
\text { POA }\end{array}$ & 4 & 5,6 \\
\hline Fora do país & 1 & 1,4 \\
\hline
\end{tabular}

Referente à naturalidade dos(as) participantes, $40(55,6 \%)$ nasceram em municípios do interior do Rio Grande do Sul; 20 (27,8\%) em Porto Alegre (POA), capital do RS; 5 (6,9\%) em outros estados; e $7(9,7 \%)$ tiveram sua resposta desconsiderada, pois responderam quanto à nacionalidade e não quanto à naturalidade. Comparativamente a estes dados, atualmente $46(63,9 \%)$ residem em Porto Alegre; 11 (15,3\%) em municípios do interior do RS; $4(5,6 \%)$ na Região Metropolitana de Porto Alegre; 10 (13,9\%) em outros estados - sendo 9 deles(as) nas capitais desses estados; e apenas $1(1,4 \%)$ fora do país (em Portugal).

Quanto às instituições de graduação, metade dos(as) participantes, 36 (50\%), cursou a graduação em faculdades ou universidades em cidades do interior do RS; 27 (37,5\%) participantes realizaram seus cursos de graduação em POA; $8(11,1 \%)$ na região metropolitana de POA; e $1(1,4 \%)$ em outro Estado (São Paulo).

A análise da naturalidade e local de graduação, relacionados ao local de moradia atual, indicam a concentração de possibilidades de emprego nos grandes centros urbanos, causando um distanciamento das cidades do interior do estado, onde muitos(as) participantes da pesquisa viveram até o final da graduação. Mundialmente, há uma defasagem de profissionais de saúde em zonas rurais e remotas (Sociedade Brasileira de Medicina de família e Comunidade, 2018) e, no Brasil, salários incompatíveis com a dinâmica do mercado de trabalho na região e seu entorno, a precariedade dos vínculos trabalhistas e a ausência de planos de 
cargos e carreiras, constituem-se como dificuldades para a fixação dos(as) profissionais em áreas remotas, sendo um aspecto que limita o acesso e a universalização da atenção em saúde (Senna, Costa, \& Silva, 2010) e demanda ações governamentais que favoreçam a fixação em municípios menores e distantes dos grandes centros urbanos.

Inserção no mundo do trabalho em saúde:

Sobre a inserção prévia em vagas de trabalho na saúde, em sua área de graduação, antes de ingressar no programa de residência do qual é egresso(a), 44 $(61,1 \%)$ responderam que não haviam trabalhado anteriormente e 28 (38,9\%) referiram já haver trabalhado. Esse dado tem grande relevância ao ser comparado aos 49 egressos(as) $(68,1 \%)$ que referem inserção no mundo do trabalho em saúde após a conclusão da RMS, pois atende ao preconizado pela lei que cria as RMS em 2005, Lei n. 11.129 (2005) que, em seu artigo 13 , inciso $1^{\circ}$ coloca que a RMS "constitui-se em um programa de cooperação intersetorial para favorecer a inserção qualificada dos jovens profissionais da saúde no mercado de trabalho, particularmente em áreas prioritárias do Sistema Único de Saúde" (Lei n. 11.129, 2005, Art. 13- $§ 1^{\circ}$, online).
Os(as) egressos(as) que hoje estão inseridos(as) no campo da saúde, 27 $(55,2 \%)$ iniciaram o trabalho logo após o término da Residência; $6(12,2 \%)$ de 0 a 1 ano após o término; $10(20,4 \%)$ de 1 a 2 anos; e $6(12,2 \%)$ mais de 2 anos após a conclusão da formação.

$$
\text { Considerando os(as) }
$$
egressos(as) de RMS que referem estar trabalhando no campo da saúde, 2 (4\%) estão há menos de um ano no serviço atual; $3(6,2 \%)$ de 1 a 2 anos; e os outros 44 $(89,8 \%)$ há mais de 2 anos. Este dado ganha relevância, pois aponta para vinculações mais estáveis de trabalho, fundamentais para a longitudinalidade do cuidado em saúde. A respeito das modalidades de contratos a que se vinculam, $21(42,85 \%)$ referem vínculo como estatutários; 18 (36,73\%) CLT; 3 $(6,12 \%)$ prestação de serviço; 2 (4,08\%) bolsistas; $2(4,08 \%)$ indicam ser concursados(as), mas não especificam o tipo de vínculo de trabalho constituído com os(as) empregadores(as); e 3 (6,12\%) denotam falta de compreensão quanto à questão formulada pela pesquisa. Ressaltamos que, dos(as) 49 que trabalham atualmente na saúde, 2 participantes referem possuir 2 diferentes vínculos de contratação, com cargas horárias distintas. Quanto à quantidade de horas de trabalho, $29(59,18 \%)$ mencionam 
contratos com regime de $40 \mathrm{~h}$ semanais; 4 $(8,16 \%)$ de $36 \mathrm{~h} ; 12(24,49 \%)$ de $30 \mathrm{~h} ; 1$ $(2,04 \%)$ de $24 \mathrm{~h} ; 3(6,12 \%)$ de $20 \mathrm{~h} ;$ e 1 $(2,04 \%)$ de 8 h e $1(2,04)$ de $15 \mathrm{~h}$.

Os municípios mencionados como locais atuais de trabalho dos(as) 49 egressos(as) estão localizados na capital do estado e região metropolitana para 31 pessoas $(53,25 \%)$; e interior do RS para 12 pessoas (24,48\%). Ainda, cinco (5) participantes referem trabalhar em outros estados $(10,2 \%)$, sendo 4 deles em capitais e $1(2,04 \%)$ não referiu a localidade.

Ao questionamento sobre a compatibilidade do salário atual com o trabalho realizado, $25(51 \%)$ responderam que consideram compatível e 24 (49\%) consideram não ser.

Outro aspecto importante a ressaltar é que dos(as) 72 participantes, 20 $(27,8 \%)$ atualmente exercem funções de tutor(a)/preceptor(a) em algum programa de RMS, contribuindo com a formação de outros(as) profissionais de saúde a partir de sua experiência prévia como residentes, indicando uma valorização do processo formativo realizado.

Avaliação quanto à formação em RMS:

No que se refere à avaliação do processo de formação realizado no programa de RMS em que estiveram inseridos(as), 28 (38,9\%) consideraram ótima, 27 (37,5\%) muito boa, $16(22,2 \%)$ boa e 1 pessoa $(1,4)$ não respondeu. Os(as) participantes atribuem grande importância à formação em programas de residência multiprofissional, nos quais são vivenciadas as dificuldades e as potencialidades do trabalho em equipe, permitindo o reconhecimento da interdisciplinaridade para o enfrentamento de problemas complexos, a ampliação do trabalho com foco nos(as) usuários(as), a possibilidade experimentar aspectos do trabalho em saúde relacionados à gestão, ao cuidado, ao planejamento e ao controle social, que propiciam aos(às) egressos(as) uma inserção qualificada em diversos âmbitos do SUS e de outras políticas públicas da rede intersetorial.

\section{Considerações Finais}

A realização da pesquisa da qual emergem os dados apresentados neste artigo aponta elementos importantes para a avaliação do processo de formação de trabalhadores(as) das profissões da saúde de nível superior, produzido nas Residências Multiprofissionais em Saúde no Brasil, relacionados ao perfil dos(as) egressos(as).

Visualizamos que esse perfil se caracteriza por uma preponderância no 
número de mulheres, brancas, com idades entre os 20 a 28 anos; que são oriundos(as) de 10 cursos de graduação da área da saúde; concluíram sua graduação majoritariamente em instituições públicas localizadas em cidades do interior do estado do RS, porém se inserindo em postos de trabalho no campo da saúde mais próximos da capital do Estado após a conclusão da residência.

Apesar de atenderem à faixa etária preconizada quando da produção de legislação que criou as RMS no Brasil e espelharem as características de inserção dos(as) trabalhadores(as) presentes no campo da saúde, de maioria feminina, ressalta-se a pouca presença de pessoas negras entre os(as) profissionais egressos(as). Esse dado é importante, pois aponta a relevância de os Programas investirem na instituição de processos de inclusão de cotas raciais em seus processos seletivos, visando enfrentar o racismo estrutural da sociedade brasileira que produz enormes desigualdades sociais e afasta do campo da saúde trabalhadores(as) negros e negras com formação universitária. Essa estratégia é de fundamental importância para favorecer a identificação dos(as) usuários(as) com os trabalhadores(as), tendo em vista que grande parte da população negra depende do Sistema Único da Saúde (SUS)
Considerando os dados apontados quanto à questão da escolaridade de negros e negras e sua relação com a inserção no mundo do trabalho, visualiza-se a reserva de vagas para a população negra como estratégia fundamental a ser implementada por todos os programas de RMS no Brasil, pois com a implementação da Política de igualdade racial, especialmente nas universidades públicas brasileiras, o percentual de pretos(as) e pardos(as) que concluíram a graduação cresceu de 2,2\%, em 2000, para 9,3\% em 2017 (IBGE, 2018b), aumentando a possibilidade de chegada de pessoas negras também às residências multiprofissionais e consequentemente aos postos de trabalho no SUS.

Os(as) egressos(as) participantes são oriundos de 10 cursos de graduação em saúde, que possuem inserção nas equipes da Política de Atenção Básica, bem como da Política de Saúde Mental nos diversos serviços da Rede de Atenção Psicossocial (RAPS). Preocupa-nos a notícia da desconstituição do Núcleo Ampliado de Saúde da Família e Atenção Básica (NASF-AB) pelo Ministério da saúde (MS), a partir de 2020, pois o NASF, criado em 2008, é responsável pela presença de fisioterapeutas, psicólogos(as), assistentes sociais, farmacêuticos(as), nutricionistas e outras profissões na 
atenção primária, sendo responsável pela presença destes(as) profissionais na Atenção Básica. Os resultados apontam uma maior adequação das IES às diretrizes Curriculares Nacionais para os cursos da área da saúde, despertando nos(as) profissionais recém formados(as) o desejo de constituírem mais solidamente sua inserção no SUS, entretanto, se as políticas não previrem a inserção dos(as) egressos(as) em postos de trabalho o SUS, como sustentar esse desejo?

Finalmente, a inserção de $68 \%$ dos(as) egressos(as) participantes da pesquisa em postos de trabalho na saúde demonstra a relevância do processo de formação nesta modalidade de especialização, indicando a importância da manutenção do investimento nas RMS como estratégia de formação e dispositivo de produção de profissionais mais implicados(as) com o SUS e seu avanço como sistema de saúde inclusivo, integral e resolutivo. Esperamos que outros estudos abrangendo o conjunto das RMS desenvolvidas no Brasil possam ser produzidos, agregando conhecimentos sobre esse processo formativo e seus efeitos para o SUS.

\section{Referências}

Almeida, S. L. de. (2018). O que é racismo estrutural? Belo Horizonte: Letramento.

Constituição da República Federativa do Brasil. (1988/2019). [recurso eletrônico]. Brasília: Supremo Tribunal Federal, Secretaria de Documentação. Recuperado de https://www.stf.jus.br/arquivo/cms/ legislacaoConstituicao/anexo/CF.p df

Brasil. (2010). Estatuto da igualdade racial. Brasília: Senado Federal, Subsecretaria de Edições Técnicas. Recuperado de https://www2.senado.leg.br/bdsf/bit stream/handle/id/496308/00089812 8.pdf? sequence $=1$

Bruschini, M. C. A. (2007, set./dez). Trabalho e gênero no Brasil nos últimos dez anos. Cadernos de Pesquisa, 37(132), 537-572. Recuperado de https://www.scielo.br/pdf/cp/v37n1 $\underline{32 / \mathrm{a} 0337132}$

Ceccim, R. \& Bilibio, L. F. S. (2002). Articulação com o movimento estudantil da área da saúde: uma estratégia de inovação na formação de recursos humanos para o SUS. In A. A. Ferla \& S. M. S. Fagundes (Org.), Tempo de inovações: a experiência da gestão da saúde do Rio Grande do Sul (pp. 163-174). Porto Alegre: Dacasa.

Ceccim, R. B. \& Feuerwerker, L. C. M. (2004). Mudança na graduação das profissões de saúde sob o eixo da integralidade. Cadernos de Saúde Pública, 20(5), 1400-1410. Recuperado de https://www.scielosp.org/article/csp /2004.v20n5/1400-1410/pt/ 
Ceccim, R. B. (2004). Equipe de saúde: a perspectiva entre-disciplinar na produção dos atos terapêuticos. In R. Pinheiro \& R. A. de Mattos (Org.), Cuidado: as fronteiras da integralidade (pp. 259-278). São Paulo: Hucitec.

Feuerwerker, L. C. M. (2002). Além do discurso de mudança na educação médica: processos e resultados. São Paulo: Hucitec.

Feuerwerker, L. C. (2003). Educação dos profissionais de saúde hoje: problemas, desafios, perspectivas e as propostas do Ministério da Saúde. Revista da ABENO,3(1), 24-27. Recuperado de https://is.gd/UAwYvq

Gadelha, P., Noronha, J. C. de, \& Pereira, T. R. (Eds.). (2012). A saúde no Brasil em 2030: diretrizes para a prospecção estratégica do sistema de saúde brasileiro. Rio de Janeiro: FIOCRUZ, Fundação Oswaldo Cruz.

Girardi, S. N. \& Carvalho, C. L. (2002). Mercado de trabalho e regulação das profissões de saúde. In B. Negri, R. Faria, A. L. D. Viana (Org.), Recursos humanos em saúde: política, desenvolvimento e mercado de trabalho (pp. 221-256). Campinas: Editora UNICAMP.

Goulart, C. T., Silva, R. M. da, Oliveira Bolzan, M. E. de, \& Azevedo Guido, L. de (2012). Perfil sociodemográfico e acadêmico dos residentes multiprofissionais de uma universidade pública. Revista da Rede de Enfermagem do Nordeste, 13(1), 178-186. Recuperado de https://www.redalyc.org/pdf/3240/3 24027980020.pdf
Guareschi, N. M. de F., Scisleski, A. C. C., Reis, C. dos, Dhein, G., \& Azambuja, M. A. de. (2014). Psicologia, Formação, Política e Produção em Saúde. Porto Alegre: EDIPUCRS.

Instituto Brasileiro de Geografia e Estatística - IBGE. (2018a). Estatísticas de Gênero Indicadores sociais das mulheres no Brasil. Estudos e Pesquisas. Informação Demográfica e Socioeconômica, (38). Recuperado de https://biblioteca.ibge.gov.br/visual izacao/livros/liv101551_informativ o.pdf.

Instituto Brasileiro de Geografia e Estatística - IBGE. (2018b). Síntese de indicadores sociais: uma análise das condições de vida da população brasileira: 2018. Rio de Janeiro: IBGE, Coordenação de População e Indicadores Sociais. Recuperado de https://biblioteca.ibge.gov.br/visual izacao/livros/liv101629.pdf

Lei n. 8.080, de 19 de setembro de 1990. (1990, Setembro 19). Dispõe sobre as condições para a promoção, proteção e recuperação da saúde, a organização e o funcionamento dos serviços correspondentes e dá outras providências. Diário Oficial da União, Brasília -DF. Recuperado de https://www.saude.mg.gov.br/imag es/documentos/Lei\%20Federal\%20 N\%208080\%201990.pdf

Lei n. 11.129, de 30 de junho de 2005. (2005, Junho 30). Institui o Programa Nacional de Inclusão de Jovens-Pró-Jovem; cria o Conselho Nacional da Juventude-CNJ e a Secretaria Nacional de Juventude; altera as Leis $\mathrm{n}^{\circ} 10.683$, de 28 de maio de 2003, e 10.429 , de 24 de 
abril de 2002; e dá outras providências. Diário Oficial da União, Brasília - DF. Recuperado de

http://www.planalto.gov.br/ccivil_0 3/ ato20042006/2005/lei/111129.htm

Lei n. 12.288, de 20 de julho de 2010 . (2010, Julho 20). Institui o Estatuto da Igualdade Racial; altera as Leis nos 7.716, de 5 de janeiro de 1989 , 9.029, de 13 de abril de 1995, 7.347 , de 24 de julho de 1985, e 10.778. Diário Oficial da União, Brasília - DF. Recuperado de

http://www.planalto.gov.br/ccivil_0 3/_ato20072010/2010/lei/112288.htm

Lei n. 12.990, de 09 de junho de 2014. (2014, Junho 9). Reserva aos negros $20 \%$ (vinte por cento) das vagas oferecidas nos concursos públicos para provimento de cargos efetivos e empregos públicos no âmbito da administração pública federal, das autarquias, das fundações públicas, das empresas públicas e das sociedades de economia mista controladas pela União. Diário Oficial da União, Brasília - DF. Recuperado de http://www.planalto.gov.br/ccivil_0 3/ Ato20112014/2014/Lei/L12990.htm

Machado, M. H. (2000). Perfil dos médicos e enfermeiros do Programa Saúde da Família no Brasil: relatório final. Brasília: Ministério da Saúde.

Machado, M. H. (2008). Gestão do Trabalho em Saúde. In I. B. Pereira \& J. C. F. Lima. Dicionário da educação profissional em saúde (pp. 227-230). 2. ed. rev. ampl. Rio de Janeiro: EPSJV. Recuperado de http://www.epsjv.fiocruz.br/sites/de fault/files/143.pdf

Mehry, E. E. (2002). Saúde: a cartografia do trabalho vivo. São Paulo-SP: Hucitec.

Merhy, E. E. \& Feuerwerker, L. C. M. (2009). Novo olhar sobre as tecnologias de saúde: uma necessidade contemporânea. In A. C. S. Mandarino \& E. Gomberg (Orgs.), Leituras de novas tecnologias e saúde (pp. 29-74). São Cristóvão-SE: Editora UFS.

Ministério da Saúde. (2004). Secretaria de Gestão do Trabalho e da Educação na Saúde. Departamento de Gestão e da Educação na Saúde. Política de Educação e Desenvolvimento para o SUS. Caminhos para a educação Permanente em saúde. Polos de educação permanente em saúde. Brasília: Ministério da Saúde. Recuperado de http://bvsms.saude.gov.br/bvs/publi cacoes/politica2_vpdf.pdf.

Ministério da Saúde. (2005). Conselho Nacional de Saúde. Princípios e diretrizes para a gestão do trabalho no SUS (NOB/RH-SUS). 3. ed. rev. atual. - Brasília: Ministério da Saúde. Recuperado de

http://bvsms.saude.gov.br/bvs/publi cacoes/NOB_RH_2005.pdf
Peduzzi,
M. (2001).
Equipe multiprofissional de saúde: conceito e tipologia. Rev. Saúde Pública [online], 35(1), 103- 109. Recuperado de http://www.scielo.br/pdf/rsp/v35n1/ 4144.pdf. 
Portaria Interministerial n. 45, de 12 de janeiro de 2007. (2007, Janeiro 12). Dispõe sobre a Residência Multiprofissional em Saúde e a Residência em Área Profissional da Saúde e institui a Comissão Nacional de Residência Multiprofissional em Saúde. Diário Oficial da União. Brasília - DF. Recuperado de http://portal.mec.gov.br/sesu/arquiv os/pdf/residencia/portaria_45_2007 . pdf

Portaria n. 198/GM, de 13 de fevereiro de 2004. (2004, Fevereiro 13). Institui a Política Nacional de Educação Permanente em Saúde como estratégia do Sistema Único de Saúde para a formação e o desenvolvimento de trabalhadores para o setor e dá outras providências. Diário Oficial da União, Brasília - DF. Recuperado de

https://www.nescon.medicina.ufmg .br/biblioteca/imagem/1832.pdf

Quirino, R. (2012). Trabalho da mulher no Brasil nos últimos 40 anos. Revista Tecnologia e Sociedade, 8(15), 90102.

Resolução CNS n. 287, de 08 de outubro de 1998. (1998, Outubro 8). Relaciona categorias profissionais de saúde de nível superior para fins de atuação do CNS. Brasília: Ministério da Saúde/Conselho Nacional de Saúde. Recuperado de https://crefrs.org.br/legislacao/pdf/r esol_cns_287_1998.pdf

Sampieri, R. H., Collado, C. F., \& Lucio, P. B. (2013). Metodologia de Pesquisa. 5. ed. São Paulo: McGraw-Hill.

Schucman, L. V. (2014). Entre o encardido, o branco $e \quad o$ branquíssimo: branquitude, hierarquia e poder na cidade de São Paulo. 1. ed. São Paulo, SP: Editora Annablume.

Senna, M. D. C. M., Costa, A. M. D., \& Silva, L. N. D. (2010). Atenção à saúde em grandes centros urbanos: desafios à consolidação do SUS. Soc Debate, 16(1), 121-37. Recuperado de http://www.revistas.ucpel.tche.br/in dex.php/rsd/article/viewFile/341/29 $\underline{9}$

Sociedade Brasileira de Medicina de Família e Comunidade. (2018, Abril 23). Sociedade Brasileira de Medicina de Família e Comunidade. Notícia: Médicos que atuam na zona rural atendem 50\% da população do mundo. [Website Sociedade Brasileira de Medicina de Família e Comunidade] Recuperado de https://www.sbmfc.org.br/noticias/ medicos-que-atuam-na-zona-ruralatendem-50-da-populacao-domundo/.

SPSS Inc. Released 2009. (2009). PASW Statistics for Windows, Version 18.0. Chicago: SPSS Inc.

Vera Lúcia Pasini Professora Dra. adjunta do Dpto. de Psicanálise e psicopatologia, do Curso de Psicologia da UFRGS.

E-mail: verapasini@gmail.com

ORCID: https://orcid.org/0000-0002$\underline{4579-8525}$

Ana Maria Ponzoni Pretto é psicóloga graduada pelo Curso de Psicologia da UFRGS e bolsista de Iniciação Científica BIC/UFRGS vinculada ao projeto de pesquisa no periodo de 2016 a 2019.

E-mail: anaponzonipretto@gmail.com ORCID: https://orcid.org/0000-0002$\underline{1945-7022}$ 
Ana Marcela Sarria é cientista Social (UFRGS) e Acadêmica do curso de Enfermagem da UFRGS. É também bolsista CNPQ AT/NS, vinculada ao projeto no período de 06/2019 a 06/2020.

E-mail: anamarcela.sa@gmail.com

ORCID:https://orcid.org/0000-0001-8587$\underline{7634}$

Marcelo Francisco da Silva Cardoso é Prof. Dr. em Ciências do Movimento Humano na Universidade Federal do Rio
Grande do Sul, Escola de Educação Física, Fisioterapia e Dança.- Porto Alegre, RS. É também professor Adjunto do DEFI da ESEFID-UFRGS;

E-mail: marcelocardoso.esef@ gmail.com ORCID:https://orcid.org/0000-0003-0740$\underline{1758}$

Enviado em: 21/09/19- Aceito em: 13/10/20 